\title{
Some design characteristics of micro steam turbines for agricultural biomass energy conversion
}

\author{
Gabriel-Paul Negreanu ${ }^{1, *}$, Ion Oprea ${ }^{1}$, and Viorel Berbece ${ }^{1}$ \\ ${ }^{1}$ University Politehnica of Bucharest, Departament Termotechnics, Engines, Thermal and \\ Refrigeration Equipment, Adress: Splaiul Independenţei, no 313, sector 6, Romania
}

\begin{abstract}
The paper continues the study of reconversion of a $400 \mathrm{~kW}$ hot water boiler in a steam generator suitable to valorise the energy content of briquettes and pellets of agricultural biomass. After steam parameters selection (pressure, temperature, mass-flow rate), an overview of main steam machines types (axial, radial, screw, piston engine) is done. Further, a parallel design of most wide-spread ones (Laval, Curtis and radial) were performed, at different rotation speeds, in order to find the best configuration in respect with the flow section dimensions, internal efficiency and power (electrical and thermal) output. The results of the paper could be very useful for the investors in agricultural "waste-toenergy" projects in order to select appropriate technology and equipment.
\end{abstract}

\section{Introduction}

During last 15 years, the authors belong to a large research team who studied the biomass by-products (solid, liquid and gaseous) in useful energy (thermal and electrical) to be used locally or remote. One of these researches [1] was focused on mini thermal steam power plant able to give economic value to new energy willow crops developed in our Country.

In a previous recent paper [2] we focused on the feasibility to convert a hot water boiler powered by solid biomass waste into a steam generator, in order to couple it with a condensing or backpressure steam turbine. The purpose of current paper is to select the type of steam engine suitable for this task, based on design feasibility and efficiency estimation.

In a "white paper" edited by a manufacturer [3], is stipulated that the steam microturbines are commonly used to reduce the pressure of process steam, working in parallel to a conventional pressure reducing station with high reliability with a service life of 15-25 years and important cost savings related to the generated electricity.

Other equipment producers [4-5] underline the advantages of the microturbines used in district heating systems such as challenging space limitations, satisfying the reliability requirements, operational simplicity, meeting the sound criteria of equipment rooms; and a

*Corresponding author: gabriel.negreanu@upb.ro 
2 to 5 year payback investment. With all the parts into one seamless part, the volume is vastly reduced, allowing the maintenance simple, compact and affordable.

The specification of such axial (Laval and Curtis) micro-turbine-generators are revealed by other manufacturer [6-7]:

- Inlet pressure: $2-30$ [bar]

- Back Pressure: 0,1 - 15 [bar]

- Turbine speed: $12000-14400$ [rpm]

- Frequency: $50 / 60 \mathrm{~Hz}$

- Voltage: $380 \mathrm{~V} / 415 \mathrm{~V}$

Kubawara et al [8] present the design characteristics of a micro steam expander based on the screw principle, with outputs of $12-132 \mathrm{~kW}$, with internal efficiencies of $60-70 \%$.

Another manufacturer [9] gives the range of electric power for its products $(50-200$ $\mathrm{kWe}$ ) and announces other advantages:

- Efficient operation in the conditions of wet steam

- Excellent ratio power/weight

- Working life min. 100000 hours

- Full power reaction time in 10 minutes

Finally, Alford et al [10] offer a comprehensive analysis of a microturbine based upon an integral high speed air compressor, optimised by means of numerical modelling, designed, manufactured and tested in a wide range of conditions with good efficiency and endurance results.

\section{Design characteristics of axial turbines}

\subsection{Input data and initial hypothesis}

According to Figure 1 that shows the main thermal circuit of the plant, the input parameters revealed in paper [1] are:

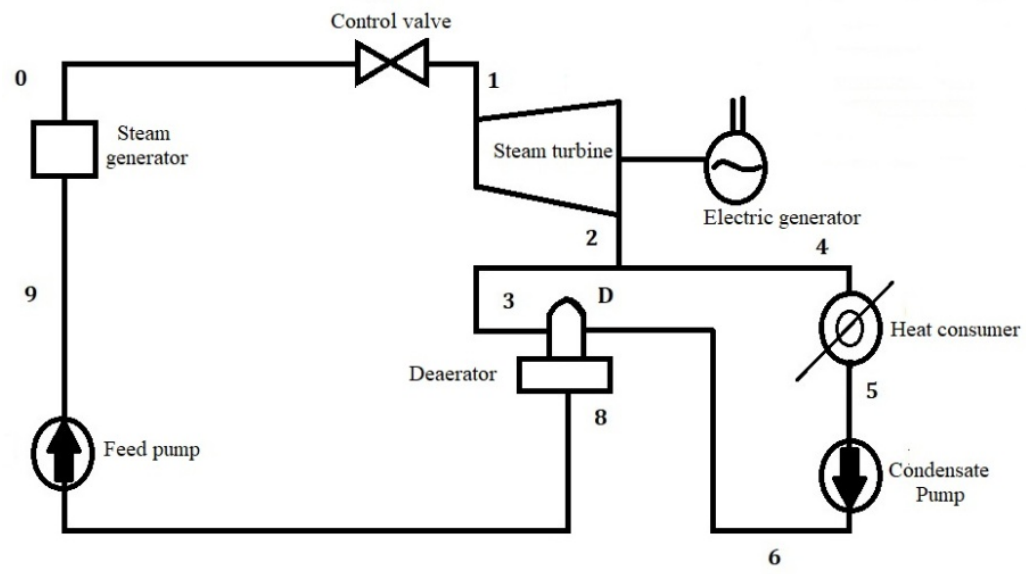

Fig. 1. Thermal circuit of the plant

- $\quad$ Live steam pressure $p_{0}=8$ [bar];

- $\quad$ Live steam vapour content $x_{0}=1[-]$ (saturated); 
- $\quad$ Exhaust pressure to the consumer $p_{2}=1.2$ [bar];

- Live steam mass flow rate $\dot{m}=0.35[\mathrm{~kg} / \mathrm{s}]$.

The two axial turbines selected for this analyse were the well known one stage Rateau and Curtis types, presented in figure 1

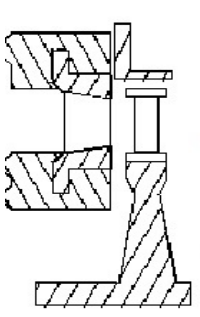

RATEAU

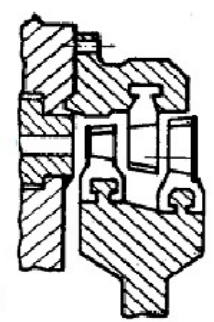

CURTIS

Fig. 2. One stage axial turbines Rateau and Curtis

Due to the very small expansion ratio $\beta=0.16<0.546=\beta_{\mathrm{cr}}$, a convergent-divergent nozzle type was selected, in order to obtain high steam velocities. The other common feature is the impulse stage type.

Meanwhile, in order be able to convert efficiently and to have small dimension, the rotation speed should be higher than $50 \mathrm{rps}$. Thus, three values were selected for this parameter, respectively 100,150 and 200 rps. It is obvious that the system should be provided with a reducing gearbox or with a frequency convertor in the electric generator.

\subsection{Methodology}

The designed methodology is inspired from [11] and is currently used in didactic and applied research activities in our University.

First of all, the optimal velocity ratio is calculated:

$$
x_{o p t}=\frac{u}{c_{1}}=k_{x} \cdot \frac{\cos \alpha_{1}}{2 \cdot i \cdot(1-\rho)}
$$

where $\quad k_{x}=0,8 \ldots 1$;

$\rho=0$ (reaction degree)

$\alpha_{1}$ - effective exit nozzle angle $\left[^{\circ}\right]$

$i$ - number of mobile rows of blades ( 1 for Rateau and 2 for Curtis)

Secondly, the absolute nozzle exit velocity can be found:

$$
c_{1}=\varphi \sqrt{2\left(H_{a}+H_{0}\right)}
$$

where $\varphi$ - nozzle losses coefficient

$H_{a}$ - nozzle isentropic drop, equal to the stage isentropic drop $H_{t}[\mathrm{~J} / \mathrm{kg}]$

$H_{0}$ - input kinetic energy [ $\left.\mathrm{J} / \mathrm{kg}\right]$

Combining eq. (1) and (2) the peripheral stage velocity $u[\mathrm{~m} / \mathrm{s}]$ allows to compute the average stage diameter $d_{1}[\mathrm{~m}]$ :

$$
d_{1}=\frac{u}{\pi \cdot n}
$$


Imposing a minimal (related to the acceptable flow losses) and constant (respecting the speed rotation $n$ ) nozzle height $L_{n 1}$ of 10 [mm] for Rateau and 20 [mm] for Curtis, from flow equation it results the criterion for establishing the optimum rate of admission $\varepsilon$ [-], meaning the ratio between the surface of nozzles exit and the whole circular crown surface available:

$$
\varepsilon L_{n 1}=\frac{\dot{m} \cdot v_{1}}{\mu \cdot \pi \cdot d_{1} \cdot c_{1} \cdot \sin 1}
$$

where $\quad \mu-$ filling surface coefficient depending on $\varphi$;

$v_{1}-$ specific volume at nozzles exit $\left[\mathrm{m}^{3} / \mathrm{kg}\right]$.

It's now possible to compute the components of velocity diagram for the two selected turbines, in order to assess both main losses $\left(\Delta H_{m}[\mathrm{~kJ} / \mathrm{kg}]\right.$ related to the nozzles, blades, exit kinetic energy and secondary losses $\left(\Delta H_{s}[\mathrm{~kJ} / \mathrm{kg}]\right.$ related to the friction and ventilation, partial admission and humidity), and also the internal enthalpy drop $H_{i}[\mathrm{~kJ} / \mathrm{kg}]$, the internal turbine efficiency $\eta_{i}[-]$ and the electric generator power $P_{g}[\mathrm{~kW}]$ :

$$
\begin{gathered}
H_{i}=H_{t}-\Delta H_{m}-\Delta H_{s} \\
\eta_{\mathrm{i}}=\frac{H_{i}}{H_{t}} \\
P_{g}=\eta_{m} \cdot \eta_{\mathrm{g}} \cdot \dot{m} \cdot H_{i}
\end{gathered}
$$

where $\quad \eta_{m}-$ mechanical efficiency [-];

$\eta_{g}-$ electric generator efficiency [-];

\subsection{Results and discussions}

The common data of the two turbines with no connection with the rotation speed are presented in Table 1:

Table 1. Common parameters non related to the speed

\begin{tabular}{|c|c|c|c|}
\hline Parameter & Unit & Rateau & Curtis \\
\hline$x_{\text {opt }}$ & {$[-]$} & 0.442 & 0.215 \\
\hline$c_{1}$ & {$[\mathrm{~m} / \mathrm{s}]$} & 734.3 & 743.8 \\
\hline$u$ & {$[\mathrm{~m} / \mathrm{s}]$} & 324.3 & 160.0 \\
\hline$\alpha_{1}$ & {$\left[^{\circ}\right]$} & 11 & 17 \\
\hline$L n 1$ & {$[\mathrm{~m}]$} & 0.01 & 0.02 \\
\hline
\end{tabular}

The other parameters depending to the rotation speed are shown in the following figures: 


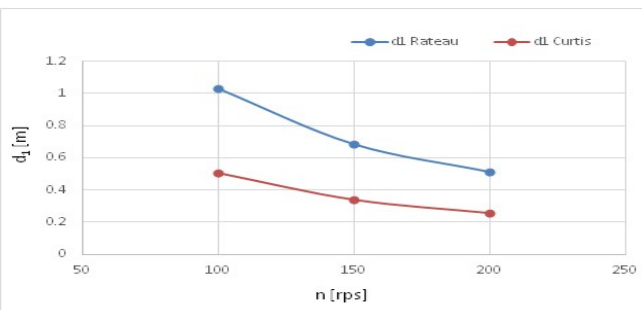

Fig. 3 Average diameter versus rotation speed

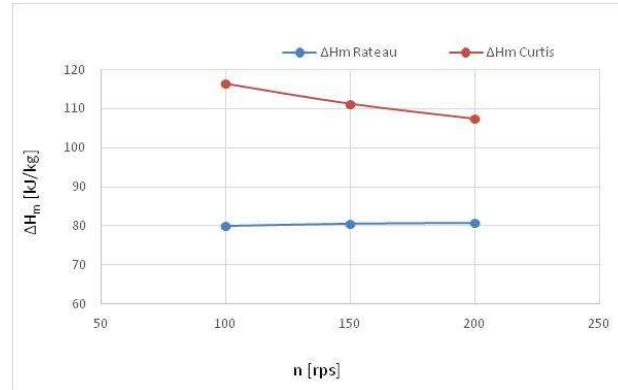

Fig. 5 Main losses versus rotation speed
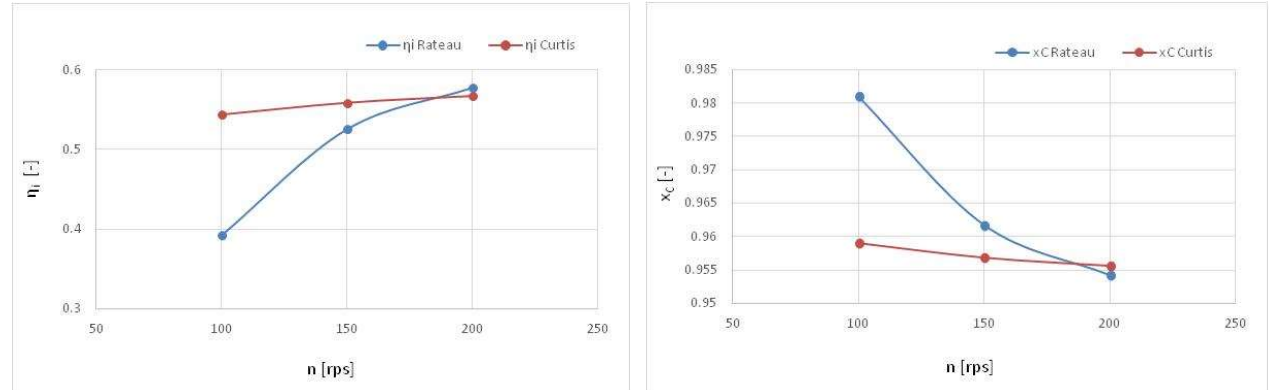

Fig. 7. Internal efficiency versus rotation speed Fig. 8 Exhaust vapour content versus rotation speed

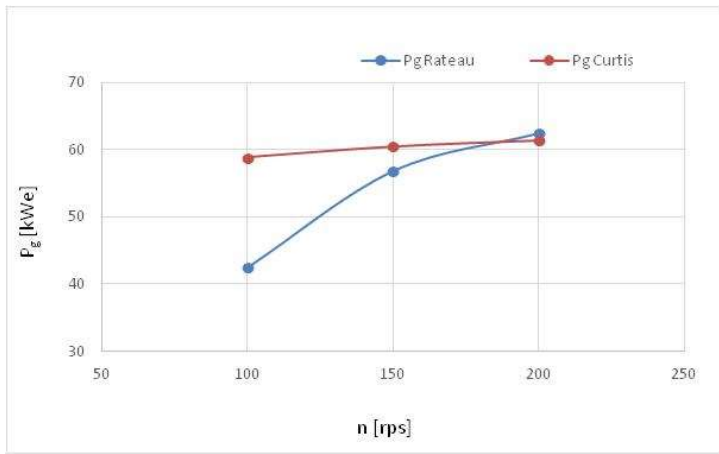

Fig. 9. Electric power versus rotation speed 
In Figure 3 is displayed the average diameter of the stage versus the rotation speed. It can be seen the diameter decrease when the speed increases, and also the smaller diameter for Curtis than Rateau.

The admission rate (Figure 4) seems to be higher for Curtis than for Rateau, but only at rotation speeds smaller than $200 \mathrm{rps}$.

The main losses, presented in Figure 5, are higher for Curtis than for Rateau, due to the three rows of blades instead of only one.

But the secondary losses, shown in Figure 6 are significant more important for Rateau than for Curtiss, due to the weight of the friction and ventilation loss, depending with $u^{3}$.

Corroborating the two last sentences, the internal efficiencies are the same at $200 \mathrm{rps}$, but Curtiss beats Rateau at lower speeds. (Figure 7)

An important parameter to be checked is represented by the vapour content at the turbine's exhaust. In order to protect the blades against the water droplets erosion its value should be higher than 0.88 . In the Figure 8 , this condition is fully respected, the smaller value registered for both turbines is about 0.955 at $200 \mathrm{rps}$. A supplementary erosion test with Esher-Wyss and Hitachi criteria confirmed this affirmation.

The final and important parameter is represented by the power delivered by the electric generator (Figure 9). At $200 \mathrm{rps}$, the values are identical for both turbines (about $62 \mathrm{~kW}_{\mathrm{e}}$ ), but at lower speeds Curtiss is more powerful than Rateau.

The overall efficiency (electric+thermal) is the same for all configuration at the value of 0.914 , that means that the biomass conversion into energy has a high efficiency in comparison with other energy conversion chains.

\section{Design characteristics of radial turbines}

A third solution analyzed was a radial-inflow turbine type. The centripetal effect makes possible to change as much energy as possible from the fluid into useful work. Some other significant advantages can be mentioned in comparison with the axial-flow turbine: a greater amount of work per stage, a simplest manufacturing, a high ruggedness and a lower cost [12]. The radial turbines are more efficient than the axial one for small mass flows and can perform large enthalpy drops with relatively low peripheral speeds. The turbine performance is a function of the similarity parameters expressed by specific speed $n_{s}$ and specific diameter $D_{s}$, and for compressible flow Reynolds number $R_{e}{ }^{*}$ and Mach number $M_{a}^{*}$.

$$
\begin{aligned}
& n_{S}=\frac{n \cdot \dot{V}_{3}^{1 / 2}}{H_{t}^{3 / 4}} \\
& D_{S}=\frac{D \cdot H_{t}^{1 / 4}}{\dot{V}_{3}^{1 / 2}}
\end{aligned}
$$

For the project data the isentropic enthalpy drop is $H_{t}=325.6 \mathrm{~kJ} / \mathrm{kg}$ and the volumetric rate of flow relative to the rotor exit is $V_{3}=0.22 \mathrm{~m}^{3} / \mathrm{s}$; the spouting velocity $c_{0}=807 \mathrm{~m} / \mathrm{s}$. In the case of ideal radial turbine, with complete recovery of the exhaust energy the optimum velocity ratio is 0.707 and the typical range is indicated $0.55<u_{2}{ }^{2} / c_{0}<0.77$ [13].

If the normal speed is considered $(n=50 \mathrm{rps})$, than the specific speed is $n_{s}=0.103$ and for Imperial units $n_{s}=1,395$ or $\Omega_{s}=0.0107 \mathrm{rad}$. The Balje diagrams $\left(n_{s} D_{s}\right.$ turbine chart) shows that this low value of specific speed is outside of the domain for the radial-inflow 
turbine with good performance [12-15]. The solution with maximum efficiency is indicated to be a partial admission axial turbine.

A high speed could be a solution for the inflow-radial turbine. A desired minimum efficiency and a corresponding specific speed can be determine on the Balje $\mathrm{N}_{\mathrm{S}}-\mathrm{D}_{\mathrm{S}}$ and Rohlick diagrams, like as $n_{s}=0.6 \mathrm{rad}$. for a total to static efficiency $\eta_{t \mathrm{~s}}=0.8$. Substituting this value, the imposed isentropic enthalpy drop and mass rate of steam flow into the $n_{s}$ equation the rotating speed of about $\mathrm{n}=3320 \mathrm{rps}$ is found. The thermal computation of the stage for a reaction degree of $\rho=0.55$ gives the fluid velocities and geometric dimensions. Mach numbers relative to the absolute velocities are slightly larger than 1, to the relative velocity $M_{w 1}=1.08, M_{w 3}=1.4$ but the inlet blade length has an unacceptable value of about $2 \mathrm{~mm}$. In these conditions a new evaluation of stage losses can decrease substantially the efficiency and the turbine solution became inacceptable.

As a conclusion the very low steam flow and the too large enthalpy drop are incompatible with the inflow radial turbine type. Splitting the enthalpy drop between two radial turbines does not significantly improve the results.

\section{Conclusions}

A lot of agricultural waste are generated yearly. The farmers use it as fuel for stoves and hot water boilers. Some of them need electricity and heat for adjacent activities (bakery, milk/meat processing, wood industry, etc.)

A good opportunity is to transform the flame tubes hot water boilers into steam generators and to couple it with microturbines.

The novelty of this paper is represented by the comparative analysis of axial and radial turbines regarding the design characteristics and operating performances. The main parameter is represented by the rotation speed.

One of the conclusions was that axial turbines are more suitable for this task in comparison with radial ones. Rateau is more simple and cheaper, Curtis is more complicate and expensive, but more robust.

The second conclusion is that higher rotation speeds (200 rps) offers compactness and better efficiencies than lower rotation speeds (100 rps).

The market offers microturbines in the power range of $15-300 \mathrm{~kW}_{\mathrm{e}}$, in multiple constructive technologies and performances. This paper can help the investors to choose one of it.

This work was supported by a grant from the Romanian Ministry of Research and Innovation, CCCDI-UEFISCDI, project number PN-III-P1-1.2-PCCDI-2017-0404/31PCCD/2018, within PNCDI.

\section{References}

1. G. Negreanu, V. Berbece, L. Mihăescu, I. Oprea, I. Pîşă, D. Andreescu, Thermal power plant for energy willow use: design, performances, Proceedings of $3^{\text {rd }}$ International Conference on Thermal Equipment, Renewable Energy and Rural Development TERE-RD 2014, 12-14 iunie 2014, Mamaia pp. 101-104, ISSN 2359-7941.

2. L. Mihăescu, G. Negreanu, I. Pîşă , V. Berbece, G. Lăzăroiu, New design of a flametube steam generator based on a hot water boiler burning agricultural waste, Proceedings of "2020 7th International Conference on Energy Efficiency and Agricultural Engineering (EE\&AE) (to be published) 
3. ***, Microturbine technology - Reduce steam pressure and generate electricity (White Paper), (www.spiraxsarco.com/uk).

4. $* * *$, MICROSTEAM ${ }^{*}$ POWER SYSTEM - Opening a New Market for Energy Recovery and On-Site Power Generation, Carrier 2008, (www.carrier.com)

5. $* * *$, Small size Steam Turbine now available, (www.innecs.com)

6. $* * *$, Steam turbine MK-3, (https://www.etgroup.nl/en/steam-turbine-mk3/)

7. $* * *$, Steam turbine MK-7, (https://www.etgroup.nl/en/steam-turbine-mk7/)

8. H. Kuwabara, M. Nishimura, M. Matsukuma, T. Matsui, Micro Steam Energy Generator, KOBELCO TECHNOLOGY REVIEW NO. 29 DEC. 2010, (https://www.kobelco.co.jp/english/ktr/pdf/ktr_29/016-022.pdf)

9. * * *, S2E I. 50-200 kW - Micro Steam Turbine \& Generator Module, (https://technopa.eu/s2e-i-50-200-kw/)

10. A. Alford, P. Nichol, B. Frisby, The Development of a Small High Speed Steam Microturbine Generator System, 2015 IOP Conf. Ser.: Mater. Sci. Eng. 90012062 (2015) (http://iopscience.iop.org/1757-899X/90/1/012062)

11. T. Grecu, M. Cârdu, I. Nicolau, Turbine cu abur (Steam turbines) - In Romanian), Editura tehnică (Technical Publishing House), Bucharest, 1976.

12. S. L. Dixon, „Fluid Mechanics and Thermodynamics of Turbomachinery”, 4th Edition. Butterworth-Heinemann, Woburn, MA, 1998

13. S. A. Korpela, „Principles of Turbomachinery”, John Wiley \& Sons, Inc., Hoboken, New Jersey, 2011

14. H. E. Rohlik, „Analytical determination of radial-inflow turbine design geometry for maximum efficiency" NASA TN D-4384, (1968);

15. E. Kenneth, P.E. Nichols, „How to Select Turbomachinery for Your Application”, Barber-Nichols Inc. Technical Papers. 